\title{
Impact of Variation in Pause Time and Network Load in AODV and AOMDV Protocols
}

\author{
P.Periyasamy \\ Department of Computer Science and Applications, Sree Saraswathi Thyagaraja College, Pollachi \\ - 642 107, Tamil Nadu, India. \\ Email: pereee@yahoo.com \\ Dr.E.Karthikeyan \\ Department of Computer Science, Government Arts College, Udumalpet - 642 126, Tamil Nadu, \\ India. \\ Email: e_karthi@yahoo.com
}

\begin{abstract}
A MANET is a collection of mobile nodes by wireless links forming a dynamic topology without any network infrastructure such as routers, servers, access points/cables or centralized administration. The communication within the network is facilitated through a protocol which discovers routes between nodes. The two major classifications of routing protocols are unipath and multipath. In this paper, the performance comparison of widely used on-demand unipath and multipath routing protocols such as AODV and AOMDV is carried out in terms of variation in pause time and network load under RWM in CBR Traffic. These protocols have been selected for simulation due to their edges over other protocols in various aspects.
\end{abstract}

Index Terms-MANET, pause time, network load, AODV, AOMDV.

\section{Introduction}

Mobile Ad hoc NETwork (MANET) is a collection of mobile nodes by wireless links forming a dynamic topology without any network infrastructure such as routers, servers, access points/cables or centralized administration. Each mobile node functions as router as well as node. The most important characteristics of MANET are i) Dynamic topologies ii) Bandwidthconstrained links iii) Energy constrained operation and iv) limited physical security $[1,2]$.

Routing protocols play a vital role in MANET to find routes for packet delivery and make sure that the packets are delivered to the correct destinations. These protocols are classified as: (i) proactive, (ii) reactive, and (iii) hybrid. Among these protocols, the reactive category is widely used because they find routes whenever needed (i.e.,on-demand). We present a simulation-based performance study of the two types of widely used reactive protocols such as AODV and AOMDV. Moreover, the performance comparison of both AODV and AOMDV is carried out with varying network load and pause time.

The rest of this paper is organized as follows: In Section 2, the major classifications of MANET routing protocols based on multiple routes are discussed; in section 3 the traffic and mobility are described; in section 4 the simulation model is discussed; in section 5 the performance metrics are described; in section 6 the experimental results are discussed and finally in section 7 the conclusion is given.

\section{Routing Protocols}

The communication within the network is facilitated through a protocol which establishes correct and efficient route between a pair of nodes so that messages may be delivered in a timely manner. The route construction should be done with a minimum of overhead and bandwidth consumption. The two major classifications of MANET routing protocols are unipath and multipath routing protocols.

\subsection{Unipath Routing Protocols}

The unipath routing protocols [2] find only a single route between a pair of source and destination. In response to every route break, a new route discovery is required which leads high overhead and latency. The two components of unipath routing protocols are i) Route Discovery: finding a route between a source and destination. ii) Route Maintenance: repairing a broken route or finding a new route in the presence of a route failure. The most commonly used unipath routing protocols are Ad Hoc On-demand Distance Vector 
(AODV) [3], Destination Sequenced Distance Vector (DSDV) [3] and Dynamic Source Routing (DSR) [3,4].

\subsubsection{The AODV Protocol}

The AODV [3] protocol is a simple and widely used on-demand unipath routing protocol that starts a route discovery process through a route request (RREQ) to the destination throughout the network when needed for MANE. Once a non-duplicate RREQ is received, the intermediate node records the previous hop and checks for a valid and fresh route entry to the destination. The node sends a route reply (RREP) along with a unique sequence number to the source. On updating the route information, it propagates the route reply and gets additional RREPs if a RREP has either a larger destination sequence number (fresher) or a shorter route found.

\subsection{Multipath Routing Protocols}

The multipath routing protocols [2] find multiple routes between a pair of source and destination in order to have load balancing to satisfy Quality of Service (QoS) requirements. The three main components of multipath routing protocols are i) Route Discovery: finding multiple nodes disjoint, links disjoint, or non-disjoint routes between a source and destination. ii) Traffic Allocation: Once the route discovery is over, the source node has selected a set of paths to the destination and then begins sending data to the destination along the paths. iii) Path Maintenance: regenerating paths after initial path discovery in order to avoid link/node failures that happened over time and node mobility.

The most recently used multipath algorithms are Temporarily-Ordered Routing Algorithm (TORA) [5], Split Multipath Routing (SMR) [5], Multipath Dynamic Source Routing (MP-DSR) [2,5], Ad hoc On-demand Distance Vector-Backup Routing (AODV-BR)[5] and Ad Hoc On-Demand Multipath Distance Vector Routing (AOMDV) [5].

\subsubsection{The AOMDV Protocol}

To eliminate the occurrence of frequent link failures and route breaks in highly dynamic ad hoc networks, AOMDV has been developed from a unipath path on-demand routing protocol AODV.

The AOMDV [2,5,6] protocol finds multiple paths and this involves two stages which are as follows: i) A route update rule establishes and maintains multiple loop-free paths at each node, and ii) A distributed protocol finds link-disjoint paths.

The AOMDV protocol finds node-disjoint or link-disjoint routes between source and destination. Link failures may occur because of node mobility, node failures, congestion in traffic, packet collisions, and so on. For finding node-disjoint routes, each node does not immediately reject duplicate RREQs. A node-disjoint path is obtained by each RREQ, arriving from different neighbor of the source because nodes cannot broadcast duplicate RREQs. Any two RREQs arriving at an intermediate node through a different neighbor of the source could not have traversed the same node. To get multiple link-disjoint routes, the destination sends RREP to duplicate RREQs regardless of their first hop. For ensuring link-disjointness in the first hop of the RREP, the destination only replies to RREQs arriving through unique neighbors. The RREPs follow the reverse paths, which are node-disjoint and thus link-disjoint after the first hop. Each RREP intersects at an intermediate node and also takes a different reverse path to the source to ensure link-disjointness.

The protocols AODV and AOMDV have been selected due to their edges over other protocols in various aspects. The comparison of AODV and AOMDV protocol is carried out in terms of variation in pause time and network load under Random Way point Mobility (RWM) in CBR Traffic. To analyze these protocols, traffic patterns and mobility models are essential and are discussed in subsequent sections.

\section{Traffic and Mobility}

\subsection{Traffic}

Traffic Patterns describe how the data is transmitted from source to destination. The widely used traffic pattern in MANET is CBR.

\subsubsection{Constant Bit Rate (CBR)}

The qualities of Constant Bit Rate (CBR) traffic pattern $[7,8]$ are i) unreliable: since it has no connection establishment phase, there is no guarantee that the data is transmitted to the destination, ii) unidirectional: there will be no acknowledgment from destination for confirming the data transmission and iii) predictable: fixed packet size, fixed interval between packets, and fixed stream duration.

\subsection{Mobility}

Mobility models describe the movement pattern of the mobile users, their location; velocity and acceleration $[9,10]$. They play a vital role in determining the performance of a protocol and also differentiated in terms of their spatial and temporal dependencies. i) Spatial dependency is a measure of how two nodes are dependent in their motion. When the two nodes are moving in the same direction, then they have high spatial dependency. ii) Temporal dependency is a measure of how current velocity (magnitude and direction) are related to previous velocity. The two nodes are having the same velocity and direction means that they have high temporal dependency. The commonly used mobility model in MANET is RWM.

\subsubsection{Random Way point Mobility (RWM)}

RWM [10] model is the commonly used mobility model in which every node randomly chooses a destination and moves towards it from a uniform distribution $\left(\mathbf{0}, \boldsymbol{V}_{\text {max }}\right)$ at any moment of time, where $\boldsymbol{V}_{\text {max }}$ is the maximum allowable velocity for every node. Each node stops for a duration defined by the 'pause time' 
parameter when it reaches the destination. After the pause time it again chooses a random destination and repeats the whole process until the end of the simulation.

\section{Simulation Model}

The comparison of AODV and AOMDV is carried out in terms of RWM and CBR traffic using NS 2 [11,12,13] and Bonn Motion [14]. The following Fig.1 illustrates the simulation model [15] and the simulation scenarios are described in Table 1 and Table 2.

The result of simulation is generated as trace files and the awk \& perl scripts are used for report generation.

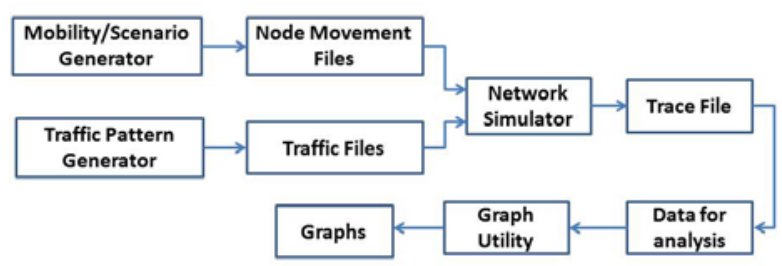

Fig 1: Overview of the simulation model.

Table 1: Simulation Scenario 1

\begin{tabular}{|l|l|}
\hline Parameter & Value \\
\hline Simulator & NS 2.34 \\
\hline MAC Type & 802.11 \\
\hline Simulation Time & 100 seconds \\
\hline Channel Type & Wireless Channel \\
\hline Routing Protocol & AODV,AOMDV \\
\hline Antenna Model & Omni \\
\hline Simulation Area & 1520 m x 1520 m \\
\hline Traffic Type & CBR \\
\hline Data Payload & 512 bytes/packet \\
\hline Network Loads & 4 packets/sec \\
\hline Radio Propagation Model & TwoRayGround \\
\hline Interface Queue Length & 50 \\
\hline Interface Queue Type & DropTail/PriQueue \\
\hline Number of nodes & 25 \\
\hline Pause Time & $0,10,20,40,60,80,100$ sec \\
\hline Mobility Model & Random Way point Mobility \\
\hline
\end{tabular}

Table 2: Simulation Scenario 2

\begin{tabular}{|l|l|}
\hline \multicolumn{2}{|c|}{ Pable 2: Simulation Scenario 2 } \\
\hline Simulator & Value \\
\hline MAC Type & 802.34 \\
\hline Simulation Time & 100 seconds \\
\hline Channel Type & Wireless Channel \\
\hline Routing Protocol & AODV,AOMDV \\
\hline Antenna Model & Omni \\
\hline Simulation Area & 1520 m x 1520 m \\
\hline Traffic Type & CBR \\
\hline Data Payload & 512 bytes/packet \\
\hline Network Loads & $1,2,3,4,5$ packets/sec \\
\hline Radio Propagation Model & TwoRayGround \\
\hline Interface Queue Length & 50 \\
\hline Interface Queue Type & DropTail/PriQueue \\
\hline Number of nodes & 25 \\
\hline Pause Time & 20 sec \\
\hline Mobility Model & Random Way point Mobility \\
\hline
\end{tabular}

\section{Performance Metrics}

Performance Metrics [16] are quantitative measures that can be used to evaluate any MANET routing protocol. The following six metrics are considered in order to compare the performance of unipath and multipath ondemand routing protocols AODV and AOMDV respectively in terms of variation in Pause Time (PT) and Network Load (NL) under RWM in CBR Traffic. The number of bits transferred per second through the traffic medium is called 'network load and the time taken by a node to choose the destination for packet delivery is called 'pause time`

\subsection{Packet Delivery Fraction (PDF)}

$\mathrm{PDF}$ is the ratio of data packets delivered to the destination to those generated by the sources and is calculated as follows: Packet Delivery Fraction $=\frac{\text { Number of Packets Received }}{\text { Number of PacketsSent }} \times 100$.

\subsection{Average Throughput (TP)}

Average Throughput [17] is the number of bytes received successfully and is calculated by

$$
\text { Average Throughput }=\frac{\text { Number of bytes received } \times 8}{\text { Simulation time } \times 1000} \mathrm{kbps} \text {. }
$$

\subsection{Routing Overhead (ROH)}

Routing overhead is the total number of control packets or routing packets generated by routing protocol during simulation and is obtained by

Routing Overhead $=$ Number of RTR packets.

\subsection{Normalized Routing Overhead (NROH)}

Normalized Routing Overhead is the number of routing packets transmitted per data packet towards destination and calculated as follows:

Normalized Routing Overhead $=\frac{\text { Number of Routing Packets }}{\text { Number of Packets Received }}$.

\subsection{Average End-to-End Delay (e2e delay)}

Average End-to-End [18] delay is the average time of the data packet to be successfully transmitted across a MANET from source to destination. It includes all possible delays such as buffering during the route discovery latency, queuing at the interface queue, retransmission delay at the MAC (Medium Access Control), the propagation and the transfer time. The average e2e delay is computed by,

$$
D=\frac{\sum_{i=1}^{n}\left(R_{i}-S_{i}\right)}{n} m \text { sec, }
$$

Where $\mathrm{D}$ is the average end-to-end delay, $n$ is the number of data packets successfully transmitted over the MANET, ' $i$ ' is the unique packet identifier, $R i$ is the time at which a packet with unique identifier ' $i$ ' is received and $S_{i}$ is the time at which a packet with unique identifier ' $i$ ' is sent. The Average End-to-End Delay should be less for high performance. 


\subsection{Packet Loss (PL)}

Packet Loss is the difference between the number of data packets sent and the number of data packets received. It is calculated as follows:

Packet Loss= Number of data packets sent- Number of data packetsreceived.

\section{Results and Discussion}

The performance of AODV and AOMDV protocols are evaluated in terms of variation in pause time and network load in CBR traffic under RWM. Table 3(a) and Table 3(b) shows the observed values of AODV and AOMDV protocols with respect to varying network load based on simulation. Table 4(a) and Table 4(b) shows the observed values of AODV and AOMDV protocols with respect to varying pause time based on simulation.

Table 3 (a): Performance data of AODV protocol with respect to NL

\begin{tabular}{|c|c|c|c|c|c|c|}
\hline NL & $\begin{array}{c}\text { PDF } \\
(\%)\end{array}$ & $\begin{array}{c}\text { TP } \\
(\mathrm{kbps})\end{array}$ & $\begin{array}{c}\text { ROH } \\
(\mathrm{pkts})\end{array}$ & $\begin{array}{c}\text { NROH } \\
(\%)\end{array}$ & $\begin{array}{c}\text { e2e delay } \\
(\mathrm{ms})\end{array}$ & $\begin{array}{c}\text { PL } \\
(\mathrm{pkts})\end{array}$ \\
\hline 1 & 53.5587 & 12.34 & 213 & 0.707641 & 92.0065 & 261 \\
\hline 2 & 52.6316 & 24.18 & 444 & 0.752542 & 262.762 & 531 \\
\hline 3 & 53.1288 & 36.21 & 660 & 0.747452 & 245.207 & 779 \\
\hline 4 & 52.1333 & 48.05 & 934 & 0.796249 & 235.886 & 1077 \\
\hline 5 & 52.4133 & 60.08 & 1183 & 0.806958 & 235.734 & 1331 \\
\hline
\end{tabular}

Table 3(b): Performance data of AOMDV protocol with respect to NL

\begin{tabular}{|c|c|c|c|c|c|c|}
\hline NL & $\begin{array}{c}\text { PDF } \\
(\%)\end{array}$ & $\begin{array}{c}\text { TP } \\
(\mathrm{kbps})\end{array}$ & $\begin{array}{c}\text { ROH } \\
(\mathrm{pkts})\end{array}$ & $\begin{array}{c}\text { NROH } \\
(\%)\end{array}$ & $\begin{array}{c}\text { e2e delay } \\
(\mathrm{ms})\end{array}$ & $\begin{array}{c}\text { PL } \\
(\mathrm{pkts})\end{array}$ \\
\hline 1 & 51.6814 & 11.96 & 262 & 0.89726 & 9.89801 & 273 \\
\hline 2 & 51.4286 & 23.61 & 516 & 0.895833 & 12.9667 & 544 \\
\hline 3 & 51.8429 & 35.16 & 761 & 0.886946 & 15.8564 & 797 \\
\hline 4 & 52.0161 & 47.57 & 1022 & 0.880276 & 14.2446 & 1071 \\
\hline 5 & 51.5335 & 59.2 & 1295 & 0.896194 & 15.4594 & 1359 \\
\hline
\end{tabular}

Table 4 (a): Performance data of AODV protocol with respect to PT

\begin{tabular}{|c|c|c|c|c|c|c|}
\hline PT & $\begin{array}{c}\text { PDF } \\
(\%)\end{array}$ & $\begin{array}{c}\text { TP } \\
(\mathrm{kbps})\end{array}$ & $\begin{array}{c}\text { ROH } \\
(\mathrm{pkts})\end{array}$ & $\begin{array}{c}\text { NROH } \\
(\%)\end{array}$ & $\begin{array}{c}\text { e2e delay } \\
(\mathrm{ms})\end{array}$ & $\begin{array}{c}\text { PL } \\
(\mathrm{pkts})\end{array}$ \\
\hline 0 & 0 & 0 & 1848 & 0 & 0 & 2245 \\
\hline 10 & 7.8877 & 7.27 & 1734 & 9.79661 & 0 & 2067 \\
\hline 20 & 52.1333 & 48.05 & 934 & 0.796249 & 235.886 & 1077 \\
\hline 40 & 12.5113 & 11.4 & 1544 & 5.55396 & 0.059603 & 1944 \\
\hline 60 & 14.7387 & 19.16 & 1523 & 4.61515 & 1.54794 & 1909 \\
\hline 80 & 31.2811 & 28.3 & 1310 & 1.8958 & 2.37255 & 1518 \\
\hline 100 & 11.3677 & 10.49 & 1724 & 6.73438 & 0 & 1996 \\
\hline
\end{tabular}

Table 4 (b): Performance data of AOMDV protocol with respect to PT

\begin{tabular}{|c|c|c|c|c|c|c|}
\hline PT & $\begin{array}{c}\text { PDF } \\
(\%)\end{array}$ & $\begin{array}{c}\text { TP } \\
(\mathrm{kbps})\end{array}$ & $\begin{array}{c}\text { ROH } \\
(\mathrm{pkts})\end{array}$ & $\begin{array}{c}\text { NROH } \\
(\%)\end{array}$ & $\begin{array}{c}\text { e2e delay } \\
(\mathrm{ms})\end{array}$ & $\begin{array}{c}\text { PL } \\
(\mathrm{pkts})\end{array}$ \\
\hline 0 & 0 & 0 & 2114 & 0 & 0 & 2229 \\
\hline 10 & 7.77827 & 7.14 & 1973 & 11.3391 & 0 & 2063 \\
\hline 20 & 52.0161 & 47.57 & 1022 & 0.880276 & 14.2446 & 1071 \\
\hline 40 & 12.5278 & 11.55 & 1858 & 6.58865 & 0.23325 & 1969 \\
\hline 60 & 14.1368 & 18.18 & 1771 & 5.67628 & 1.44004 & 1895 \\
\hline 80 & 30.8072 & 28.15 & 1485 & 2.16157 & 2.39711 & 1543 \\
\hline 100 & 11.1061 & 10.14 & 1895 & 7.67206 & 0 & 1977 \\
\hline
\end{tabular}

The comparison results of AODV and AOMDV protocols are described in terms of six performance metrics by graphs and are discussed below.

\subsection{Packet Delivery Fraction}

Fig. 2(a) and Fig. 2(b) shows the delivery rate of the data packets of AODV and AOMDV in terms of variation in pause time and network load under RWM in CBR Traffic respectively. The Packet Delivery rate needs to be high for effective performance of routing. Variation in pause time gives same impact in both AODV and AOMDV protocols where as variation in network load gives a significant impact for AODV protocol.

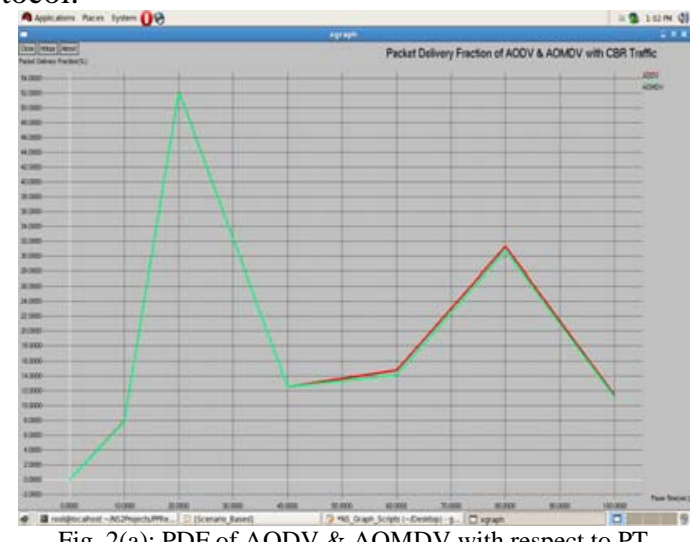

Fig. 2(a): PDF of AODV \& AOMDV with respect to PT

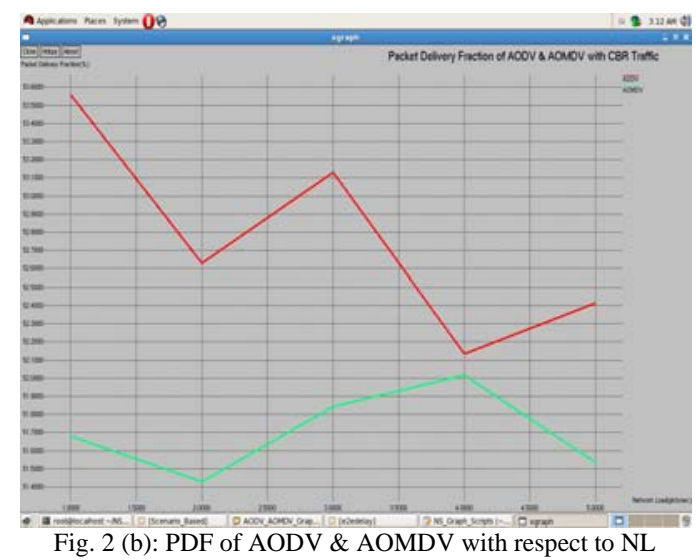

\subsection{Average End to End Delay}

The End to End Delay is a significant parameter for evaluating a protocol which must be low for good performance. From Fig. 3(a) and Fig. 3(b), the variation in pause time and network load gives significant impact in AOMDV protocol. In other words, the AOMDV is performing well than AODV when the pause time and network load varies.

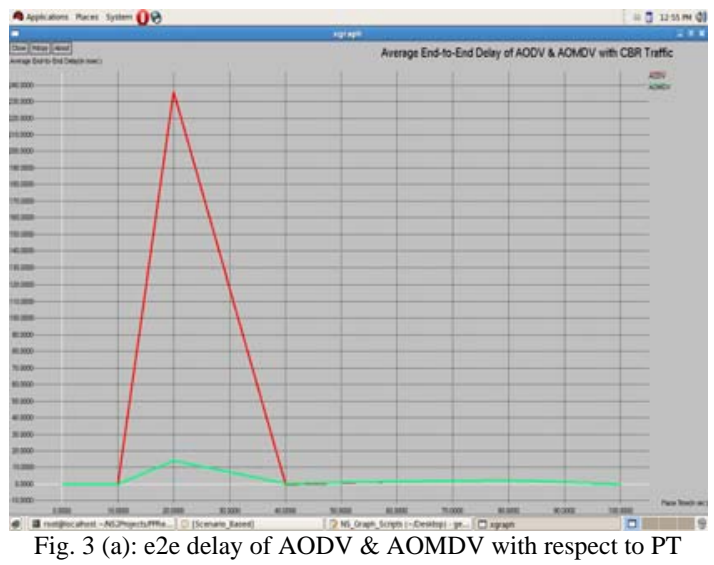




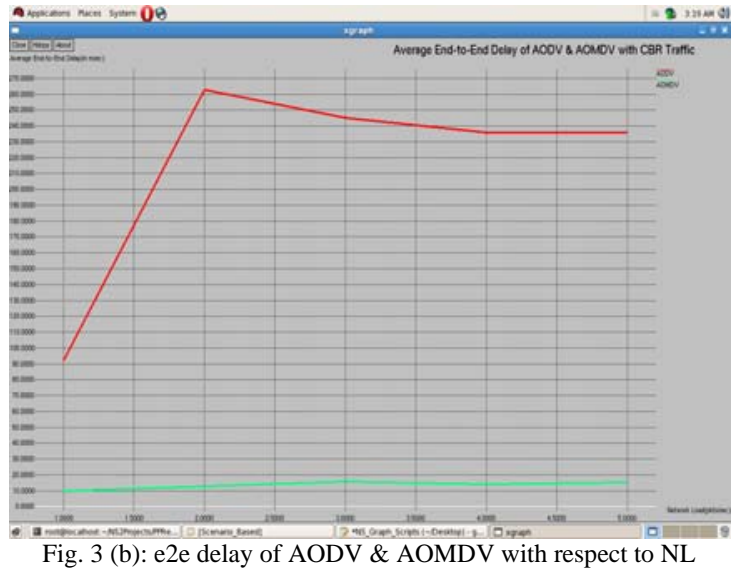

\subsection{Average Throughput}

From Fig. 4(a) and Fig. 4(b), the variation in pause time and network load gives more or less the same throughput in both AODV and AOMDV protocol. Since the AOMDV's throughput is somewhat higher than the AODV due to its multiple routes capability which is an added advantage to AOMDV protocol.

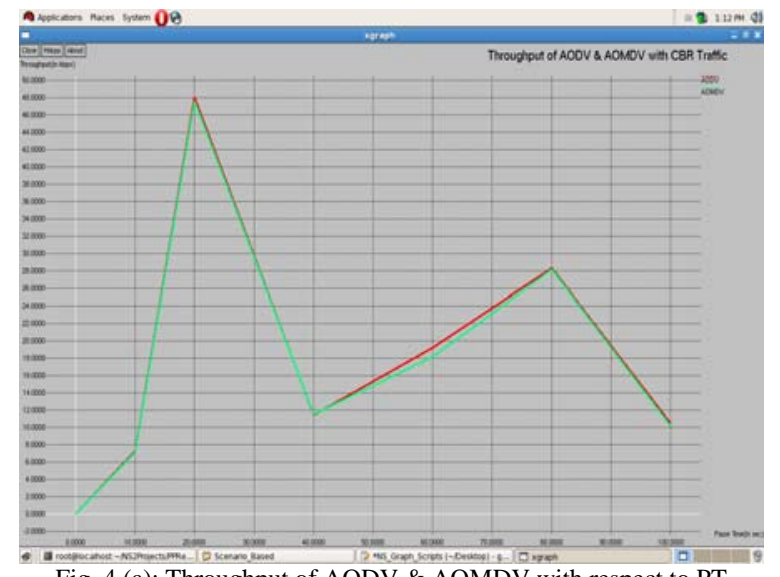

Fig. 4 (a): Throughput of AODV \& AOMDV with respect to PT

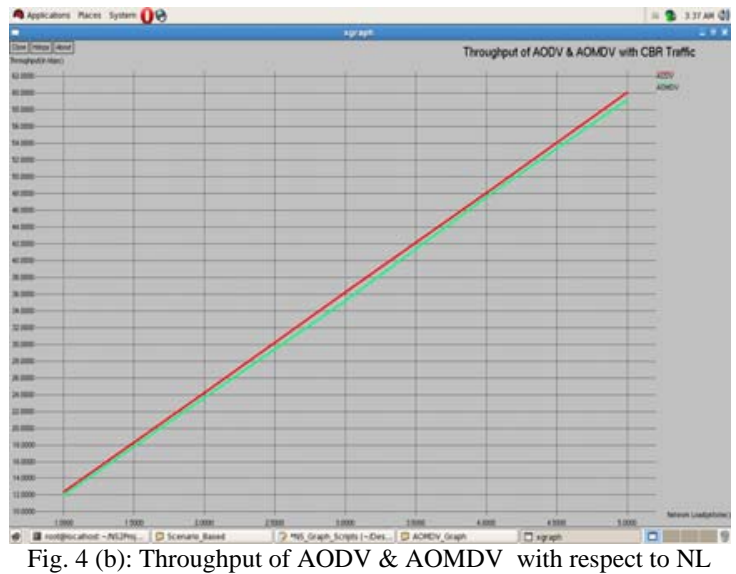

\subsection{Routing Overhead (ROH)}

From Fig. 5(a) and Fig. 5(b), the variation in pause time and network load gives considerable reduction of ROH in AOMDV protocol. From Fig.5 (a) the AOMDV's ROH is somewhat higher than the AODV due to its multiple paths. From Fig.5 (b), the ROH of
AOMDV protocol is higher than the AODV when the variation in network loads.

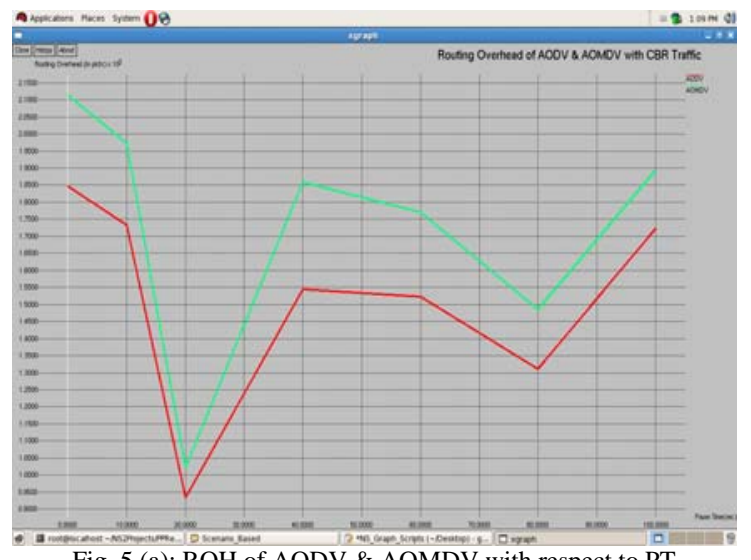

Fig. 5 (a): ROH of AODV \& AOMDV with respect to PT

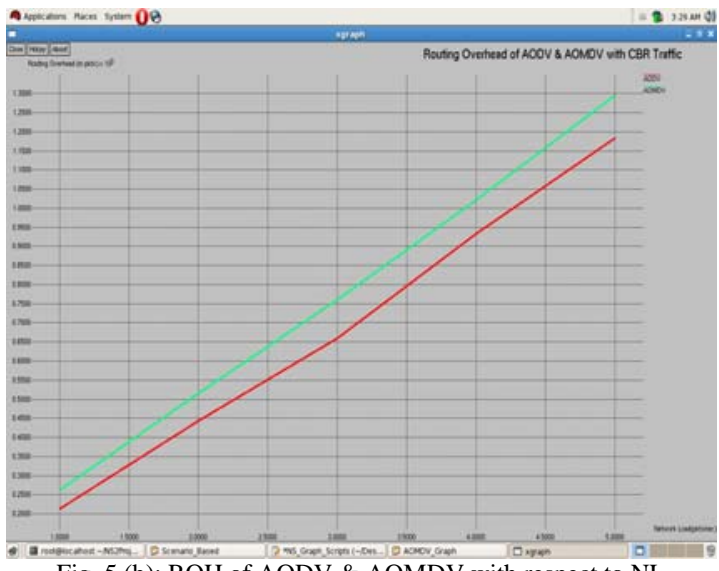

Fig. 5 (b): ROH of AODV \& AOMDV with respect to NL

\subsection{Normalized Routing Overhead (NROH)}

From Fig. 6(a) and Fig. 6(b), the variation in pause time and network load gives considerable reduction of $\mathrm{NROH}$ in AOMDV protocol. Thus the AOMDV's NROH is somewhat higher than the AODV due to its multiple routes capability.

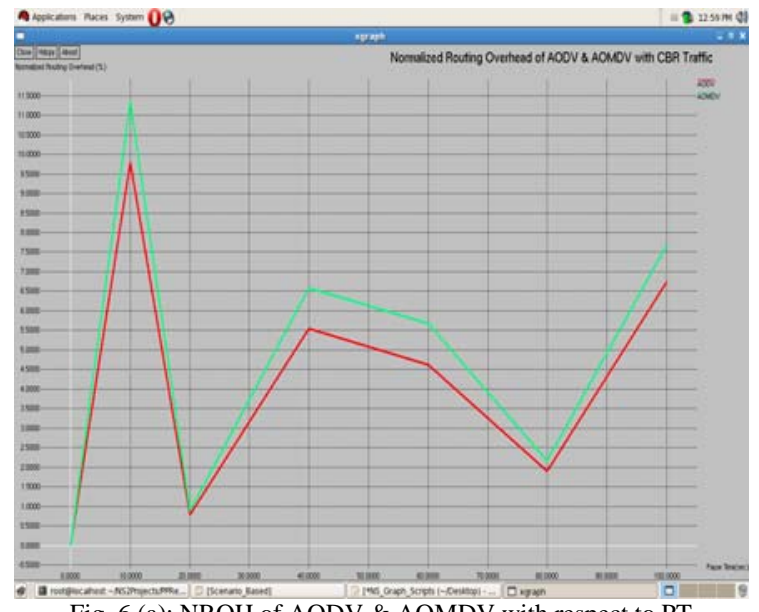

Fig. 6 (a): NROH of AODV \& AOMDV with respect to PT 


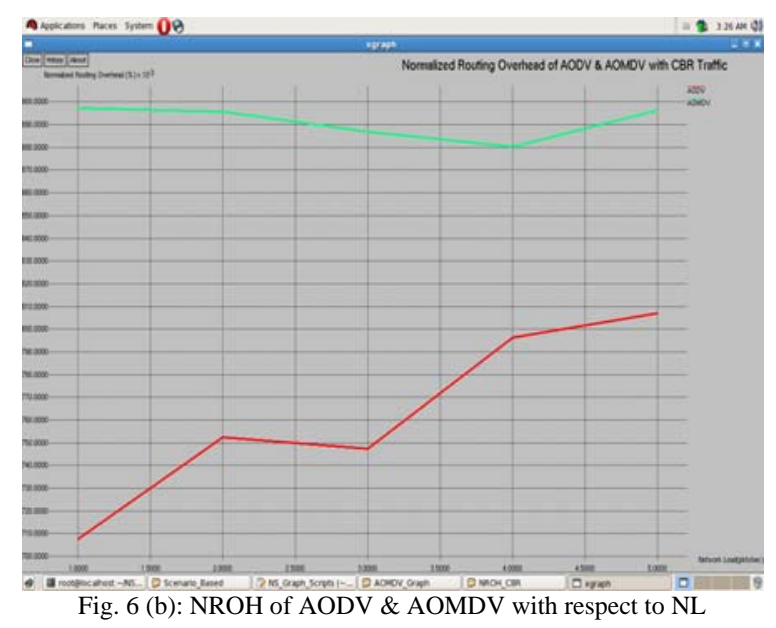

\subsection{Packet Loss}

From Fig. 7(a) and Fig. 7(b), the variation in pause time gives zigzag packet loss in AOMDV protocol where as the incremental variation in network load shows an increase in packet loss in both AODV and AOMDV protocols.

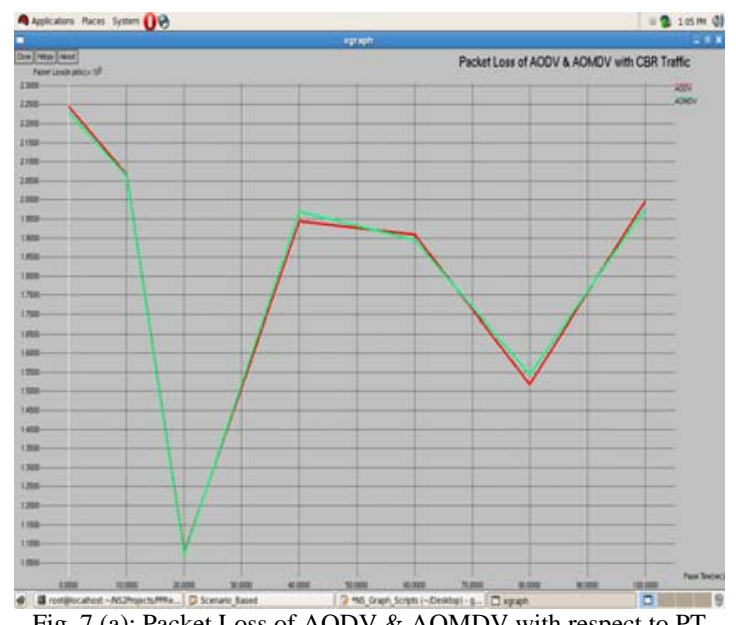

Fig. 7 (a): Packet Loss of AODV \& AOMDV with respect to PT

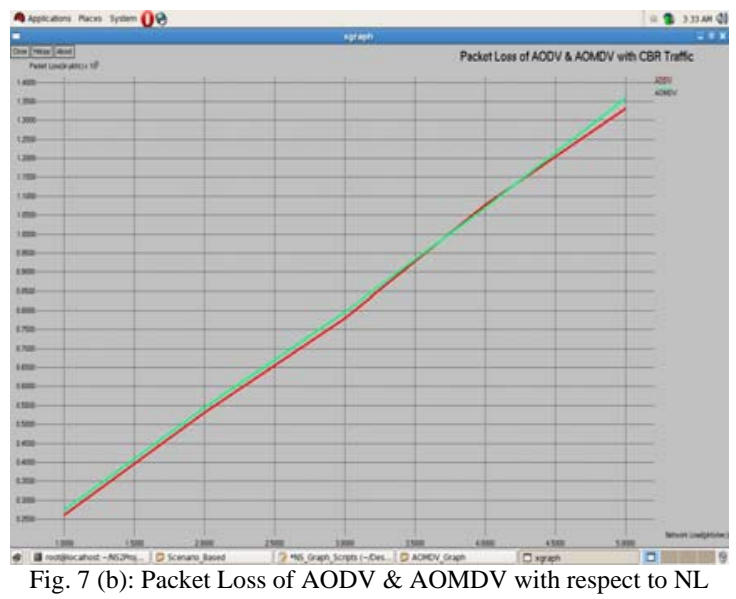

\section{Conclusions and Future Work}

The AODV and AOMDV protocols are compared in terms of the variation in pause time and network load in CBR traffic under RWM. Due to randomness in mobility, the RWM and CBR are selected as scenario parameters. The AOMDV protocol is giving better performance than the AODV protocol for most of the performance parametric measures.

The $\mathrm{ROH}$ and $\mathrm{NROH}$ parameters are comparatively high for AOMDV protocol which can be reduced by the reduction of control packets. The future work of the research will focus on the reduction of the usage of control packets in routing.

\section{References}

[1] Sapna S. Kaushik, P.R.Deshmukh, “Comparison of effectiveness of AODV, DSDV and DSR Routing Protocols in Mobile Ad hoc Networks", International Journal of Information Technology and Knowledge Management, Vol. 2(2), pp.499-502, 2009.

[2] V.C.Patil, Rajashree, V.Biradar, R.R. Mudholkar, S.R.Sawant, "On-Demand Multipath Routing Protocols for Mobile Ad Hoc Networks Issues and Comparison”, International Journal of Wireless Communication and Simulation, Vol. 2(1), pp. 2138, 2010.

[3] Elizabeth M. Royer, C-K Toh, "A Review of Current Routing Protocols for Ad-Hoc Mobile Wireless Networks”, IEEE Personal Communications, pp.46-55, April 1999.

[4] S.Corson, J.Macker, "Routing Protocol Performance Issues and Evaluation Considerations”, RFC2501, IETF Networking Group, January 1999.

[5] R.L.Lagendijik, J.F.C.M.de Jongh, "Multipath Routing in Mobile Ad Hoc Networks", Traineeship Report, Version 1.2, TU- Delft/TNO, 2003.

[6] Mohd Izuan Mohd Saad, Zuriati Ahmad Zukarnain, "Performance Analysis of Random-based Mobility Models in MANET Protocols”, European Journal of Scientific Research, Vol. 32(4), pp. 444-454,2009.

[7] Thomas Clausen, Philippe Jacquet, Laurent Viennot, "Comparative study of CBR and TCP Performance of MANET routing protocols”, Technical report, Project HiPERCOM, INRIA Rocquencourt, 2002.

[8] Vikas Singla, Parveen Kakkar, “Traffic Pattern based performance comparison of Reactive and Proactive protocols of Mobile Ad-hoc Networks", International Journal of Computer Applications, Vol. 5(10), pp.16-20, 2010.

[9] Harminder S. Bindra1, Sunil K. Maakar, A. L. Sangal , "Performance Evaluation of Two Reactive Routing Protocols of MANET using Group Mobility Model”, IJCSI International Journal of Computer Science Issues, Vol. 7(10), pp.38-43, 2010.

[10] C.P.Agrawal, O.P.Vyas, M.K.Tiwari, "Evaluation of varying mobility models \& network loads on DSDV protocol of MANETs", International Journal of Computer Science and Engineering,Vol. 1(2), pp. 40-46, 2009. 
[11] The Network Simulator ns-allinone-2.34, http://www.isi.edu/nsnam/ns/

[12] Kevin Fall, K. Varadhan, "The ns Manual", University of Southern California, Information Sciences Institute (ISI), http://www.isi.edu/nsnam/ns/ns-documentation.html.

[13] NS-2 with Wireless and Mobility Extensions, http://www.monarch .cs.cmu.edu.

[14] The Bonn Motion, http://bonnmotion.cs.unibonn.de/

[15] A.Valarmathi, RM.Chandrasekaran, "Congestion Aware and Adaptive Dynamic Source Routing Algorithm with Load Balancing in MANETs", International Journal of Computer Applications, Vol. 8(5), pp.1-4, 2010.

[16] Anuj K. Gupta, Harsh Sadawarti, Anil K. Verma, "Performance analysis of AODV, DSR \& TORA Routing Protocols”, IACSIT International Journal of Engineering and Technology, Vol. 2(2), pp.226-231, 2010.

[17] S. R. Das, R. Castaeda, J. Yan, “Simulation-based performance evaluation of routing protocols for mobile ad hoc networks", Mobile Networks and Applications, Vol. 5, pp.179-189, 2000.

[18] Sujata V.Mallapur, Sujata .Terdal, Enhanced, “AdHoc on Demand Multipath Distance Vector Routing Potocol (EAOMDV)”, International Journal of Computer Science and Information Security, Vol. 7 (3), pp.166-170, 2010.

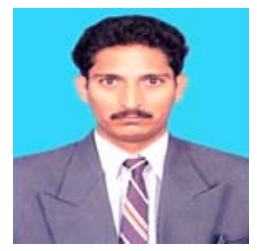

P.Periyasamy is working as an Assistant Professor in the Department of MCA, Sree Saraswathi Thyagaraja College, Pollachi, India. Interested in Mobile Ad hoc Networks Routing Protocols Design and Development.

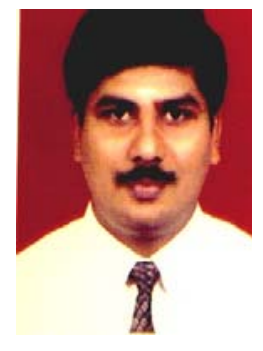

Dr.E.Karthikeyan is working as an Assistant Professor in the Department of Computer Science, Government Arts College, Udumalpet, Tamil Nadu, India. Interested in Mobile Ad hoc Networks Routing Protocols Design and Development, Network Security and Cryptography and Implementing MDC (Secured Video Streaming) over MANET. 